\title{
educação

\section{A ontologia da singularidade e a educação em Hannah Arendt: Uma preparação para o mundo}

\author{
Danilo Arnaldo Briskieviczi \\ Instituto Federal de Educação, Ciência e Tecnologia de Minas \\ Gerais, Brasil
}

\begin{abstract}
Investigamos no pensamento de Hannah Arendt a possibilidade de uma ontologia da singularidade relacionada diretamente com a educação, como protomomento da ontologia da pluralidade, iniciada com o nascimento e ampliada pela chegada ao mundo comum, ao espaço da ação. Destacamos alguns pontos de sua teoria política, inter-relacionando-os com apontamentos sobre a educação do texto A Crise da Educação, de 1958. Apresentamos a educação como espaço privilegiado de formação da vida do espírito, essencial, por ser inicial, em tempo e espaço para o exercício pleno da vita activa. A ontologia da singularidade é fundamentada a partir de seis pontos em que é preciso: acolher, preparar e incluir os singulares; fomentar espaços para o discursar, valorizar as diferenças e preservar a tradição. Apresentamos dois antimodelos para a ontologia da singularidade: na educação escolar, os campos de concentração, pela prerrogativa do uso da violência e da mudez; para os educandos, Adolf Eichmann, por causa de seu vazio de pensamento e incapacidade de agir criativamente no mundo. Propomos que a duração da educação é proporcional à criatividade narracional da tradição pela autoridade dos professores.
\end{abstract}

Palavras-chave: Hannah Arendt; Ontologia da singularidade; Filosofia da educação; Vida do espírito

\section{ORIGEM DO PROBLEMA: É POSSÍVEL UMA ONTOLOGIA DA SINGULARIDADE EM EDUCAÇÃO?}

Hannah Arendt (1906-1975) é uma pensadora contemporânea da condição humana no sentido mais amplo do termo. Ela não autoriza reducionismos conceituais. Ao se afirmar que há, em sua obra, uma ética, uma moral, uma epistemologia, uma pedagogia, uma ontologia, uma historiografia, entre outros, corre-se o risco de limitar o alcance de suas proposições e de diminuir o impacto de suas análises. A sua forma de escrever revela o fundo de seu pensamento, perpassando apropriações e negações, aceitações e contradições, concordâncias e polêmicas com diversos autores e autoras, das mais diversas tradições do pensamento, negando-se a uma sistematização reducionista.

Sabedores de sua discussão sobre a educação em um ou outro ensaio pontual, nos permitimos discutir a possibilidade de uma ontologia da singularidade em educação. Partimos da 
leitura de muitos de seus textos e de alguns de seus comentadores e críticos. Além disso, pretendemos alinhar certos conceitos, termos e categorias políticos da autora com a educação, a fim de ampliar o potencial analítico da última e realizar o balizamento com a primeira. Assim, relacionamos o pensamento político da autora com a educação, tendo como ponto de partida a afirmação de que há uma ontologia da singularidade no ato de educar, ato intermediário entre o nascimento e a ação no mundo comum.

O tema da educação em Arendt é problematizado no ensaio A Crise da Educação, publicado em 1958 (Arendt, 1992, pp. 221247). Ela percebeu que a crise da educação norteamericana era uma das cristalizações (a mais radical é o totalitarismo) da ruptura política ocidental com a tradição, com uma certa teoria da ação, de autoridade e de liberdade.

A adoção da pedagogia do pragmatismo para reformar pela educação uma sociedade em conflito espelhou a crise contemporânea em solo norte-americano. De fato, Arendt discorda do pragmatismo de John Dewey (1859-1952) e das repercussões do pensamento pedagógico dele na educação, muito pelo fato do "aprender fazendo". Para ele, "o fim (resultados) da educação se identifica com os seus meios (processos) do mesmo modo, aliás, que os fins da vida se identificam com os processos de viver" (Dewey, 1971, p. 93) e, assim, "enquanto vivo, não me estou, agora, preparando para viver daqui a pouco, estou vivendo. Do mesmo modo, eu não me estou em um momento preparando para educar-me e, em outro, obtendo o resultado dessa educação" (Dewey, 1971, p. 93). A ênfase da educação é dada ao aluno e suas experiências de vida.

Arendt critica o pragmatismo afirmando que "seja qual for a conexão entre fazer e aprender... tende a tornar absoluto o mundo da infância" (Arendt, 1992,p.242)e"sobo pretexto de respeitar a independência da criança, ela é excluída do mundo dos adultos e mantida artificialmente no seu próprio mundo" (Arendt, 1992, p. 242). A autora afirmou que a questão fundamental da crise educacional norteamericana é a da responsabilidade dos adultos em relação às crianças e jovens, em suma, a crise do amor mundi (Arendt, 2004b, pp. 213-225; Assy, 2015, pp. 20-24). Essa responsabilidade define a mediação a ser realizada entre crianças e jovens e a escola, uma vez que "a educação é o ponto em que decidimos se amamos o mundo o bastante para assumirmos a responsabilidade por ele" (Arendt, 1992, p. 247) e também "onde decidimos se amamos nossas crianças o bastante para não expulsá-las de nosso mundo e abandoná-las a seus próprios recursos" (Arendt, 1992, p. 247).

Para Arendt, a educação tradicional ocidental tem como marca a responsabilidade pelas crianças e jovens a fim de colocá-los pouco a pouco em contato com o mundo dos adultos, aquela esfera pública que existe antes da chegada deles e que permanecerá depois da morte. A função da educação é a conservação do mundo pela mediação entre adultos, crianças e jovens, pois "faz parte da essência da atividade educacional, cuja tarefa é sempre abrigar e proteger alguma coisa: a criança contra o mundo, o mundo contra a criança, o novo contra o velho, o velho contra o novo" (Arendt, 1992, p. 242). Quando a educação fica restrita ao mundo e experiências das crianças e jovens que estão ainda em formação - crítica destinada ao pragmatismo -, evidencia-se uma crise. Por isso, a responsabilidade pela introdução dos recém-chegados ao mundo é da educação e de seus dispositivos.

A ontologia da singularidade (crianças e jovens) em Arendt tem como ponto de partida o fato biológico do nascimento dos novos seres humanos no mundo que já existe e que deverá ser mediado com eles pelos adultos. A natalidade é a revelação da singularidade, da unicidade do indivíduo no mundo. O nascimento põe no mundo novas possibilidades de ação que 
precisam ser mediadas pela educação. Por isso, receber e preparar quem chegou para assumir o protagonismo no espaço público é o momento-chave em que decidimos pelo cuidado com o mundo - amor mundi, pois necessitamos educar os recém-chegados, potencialmente políticos (Almeida, 2011, p. 21; Correia, 2010, p. 817). Por isso, "a ação educativa deve ser norteada pela dimensão do público” (Rodrigues, 2008, p. 18), sem se reduzir a ela, como momento pré-político. Arendt ressalta que "uma das funções da escola é preparar as pessoas para a prática do diálogo, considerada como uma ação fundamental para a ação no espaço público" (Rodrigues, 2008, p. 18). Nesse sentido, "concebe-se assim que o espaço público é próprio para o exercício da atividade humana" (Rodrigues, 2008, p. 18). O mundo, portanto, se renova e se reconstitui pela ontogênese dos recém-chegados. A escola e a educação devem tratar da singularidade de crianças e jovens. Esse sentido é reforçado pela etimologia do substantivo singularidade, de origem latina: singularitas, singularis, que define aquilo que é único, solitário, um por um, peculiar, derivado de singulus, que define o individual, o único, derivado de sim, diminutivo da raiz do substantivo simplus, derivando o substantivo simples. A singularidade é característica do que é pouco frequente, fora do comum, extraordinário, distinto, que não tem correspondência com outro, surpreendente, incomum. É uma qualidade que distingue algo de outras coisas do mesmo gênero, ou seja, possui uma particularidade, uma originalidade, uma excentricidade (Cunha, 1986; Ferreira, 1976; Houaiss \& Villar, 2001).

A ontologia da singularidade em educação é um momento anterior (antemundano, protomundano, pré-político, pré-acional) à constituição da ontologia da pluralidade nos negócios humanos, ou seja, o mundo em que já devemos estar minimamente preparados para o uso da liberdade, para a ação. Assim, podemos afirmar que a ontologia da singularidade é uma preparação e a ontologia da pluralidade "se configura como a suma expressão e significação política da ação" (Seixas, 2009, p. 6). O que alguns comentadores de Arendt têm afirmado é que há uma ontologia da pluralidade apenas, generalizada, muito em vista da teoria da ação por ela desenvolvida e que culmina com o exercício da liberdade. E a preparação para ingressar no mundo? Pretendemos, pois, demonstrar que a ontologia da singularidade é uma condição primordial para uma ontologia da pluralidade. Ou, dito de outra forma: só podemos afirmar uma ontologia da pluralidade se antes afirmarmos a possibilidade de uma ontologia da singularidade, diante da inferência clara de que sem a ontologia da singularidade haveria uma impossibilidade da ontologia da pluralidade.

\section{O QUE É A ONTOLOGIA DA S I N G U L A R I D A DE?}

2.1 NASCEMOS INDIVÍDUOS SINGULARES OU A EDUCAÇÃo NOS SINGULARIZA?

Nascer e singularizar-se são fenômenos indistinguíveis. Contudo, uma questão se coloca a partir da lógica intrínseca entre nascer e singularizar-se. Trata-se de se questionar se Hannah Arendt se orienta filosoficamente a partir do conceito de uma natureza humana ou de uma condição humana, ou, colocado de outra maneira: nascemos essencialmente humanos ou estamos sujeitos ao desenvolvimento de novas habilidades que definirão se somos ou não humanos?

Em primeiro lugar, a concepção de uma natureza humana em termos objetivos, permanente para além do tempo e do espaço, como um paradigma metafísico, abstrato e de valor universal, predominou no mundo ocidental. Por isso, a maioria dos pensadores da Grécia Antiga, muitos dos medievais e dos iluministas do século XVIII afirmavam a existência de uma natureza humana, uma essência do ser humano imutável. 
A marca dos pensadores da natureza humana é um certo racionalismo aristotélico, ou seja, “o que mais distingue o homem dos demais animais é o fato de que ele é um ser racional" (Vicente, 2010, p. 49). Por isso, havia uma necessidade de comparar o humano com o não-humano "que, em termos aristotélicos e por uma longa tradição, é o animal" (Cavarero \& Butler, 2007, p. 650). A afirmação essencialista de uma natureza humana reverberou, por exemplo, no pensamento de Thomas Hobbes (1588-1679), ao constatar que o ser humano tem uma certa tendência natural para a destruição, derivando daí uma teoria política para controlar e harmonizar esta marca original universal através de um contrato social. Assim, "dizer que alguma coisa é natural ou por natureza significa dizer que esta coisa existe necessária e universalmente como efeito de uma causa necessária e universal” (Vicente, 2010, p. 48). Por isso, "tal coisa não depende da ação e intenção dos seres humanos" (Vicente, 2010, p. 48). Ademais, "como é da natureza dos corpos serem governados pela lei natural da gravitação universal...comoé da natureza da abelha produzir mel e da roseira produzir rosas, também seria por natureza que os homens sentem, pensam e agem" (Vicente, 2010, pp. 48-49). Contudo,

hoje... não só [se] nega que exista uma natureza humana entendida universalmente, mas tende, sobretudo, a definir o humano mais com referência ao inumano do que ao não-humano. Não se trata apenas de um jogo de palavras... O inumano, por sua vez, alude a uma negação do humano que é interna ao próprio humano. A barbárie de Auschwitz poderia servir de exemplo. Parece, aliás, que a época histórica inaugura uma reflexão sobre o humano que não pode deixar de se confrontar com o abismo da sua autonegação. É como se a natureza humana fosse uma questão que não tem a ver com o lugar da espécie humana na classificação do mundo dos seres vivos, mas sim com o modo como os humanos desvelam para si mesmos. (Cavarero \&
Butler, 2007, p. 650)

Em segundo lugar, estabeleceu-se uma outra tradição que nega a universalidade da natureza humana, afirmando que, ao nascer, os recém-chegados constituem - todos e cada um - uma condição humana, histórica, condicionada pela conjuntura social, indeterminada. Hannah Arendt contradisse a tradição essencialista desde seu primeiro livro Origens do Totalitarismo, de 1951, ao evidenciar que o totalitarismo pretendia mudar a natureza humana com a criação dos campos de concentração: "o que as ideologias totalitárias visam, portanto, não é a transformação do mundo exterior ou a transmutação revolucionária da sociedade, mas a transformação da própria natureza humana" (Arendt, 2004a, p. 509).

Portanto, entre a concepção essencialista e a concepção realista, Arendt fica com a segunda, a da condição humana. A polêmica em torno da natureza humana demonstra que a autora não se vinculou à corrente essencialista. Nesse sentido, podemos afirmar que Arendt acredita que "o homem, para viver, precisa sempre dar conta da vida e da sua reprodução; de um mundo que o proteja das intempéries da natureza e de um espaço que possibilitasse a sua interação política e linguisticamente mediada" (Aguiar, 2008, p. 32). Negando o essencialismo, em Arendt não existe "nenhuma receita de como os homens devem cuidar da sua reprodução biológica, da terra, do mundo e da esfera pública" (Aguiar, 2008, p. 32). Nesse sentido,

a condição humana é compreendida pela vita activa e pela vida do espírito e não é entendida substancialmente: não se trata de uma essência que determina todos os seres predicados por ela, pois não define um conteúdo, trata-se, antes das condições nas quais o ser humano pode viver e se realizar. (Aguiar, 2008, p. 32) 
A condição humana é situacional, uma vez que "agir e pensar são capacidades que se realizam em determinadas circunstâncias, mas essas circunstâncias jamais determinam o conteúdo da ação e do pensamento" (Aguiar, 2008, pp. 3233).

\subsection{Alguns pontos para uma ontologia} DA SINGULARIDADE

O nascimento principia a vita activa: Acolher é preciso

Propomos alguns pontos para uma reflexão acerca de uma ontologia da singularidade relacionada diretamente à educação. Todo o nascimento no mundo lança um indivíduo numa condição humana, em inter-relação constante com a cultura, com a economia, com a política, com a história. O mundo dos adultos já existe, já se encontra construído pelo trabalho e dinamizado pela ação no espaço público. $\mathrm{O}$ mundo é o espaço da pluralidade - um espaço ou esfera de convivência entre os pares, ou os diferentes. $\mathrm{O}$ indivíduo recém-chegado é singular em sua constituição ontológica diante dos demais seres humanos que já compõem o mundo. Há apenas uma determinação inicial: lançado no mundo comum aos adultos, o recémchegado principia sua vita activa (Arendt, 2005, pp. 15-26).

$\mathrm{O}$ acolhimento da singularidade pelos adultos é o início da história de cada indivíduo, pois "os recém-chegados precisam ser acolhidos e familiarizados com este espaço comum e seu legado, que futuramente estarão sob sua responsabilidade" (Almeida, 2011, pp. 20-21). A educação dos recém-chegados é uma tarefa fundamental para o mundo comum: "a tarefa da educação, portanto, é introduzir as crianças num mundo que lhes antecede e que continuará depois delas" (Almeida, 2011, p. 21). Portanto, $a$ vita activa é uma condição humana iniciada com o nascimento e o processo de ensino-aprendizagem será responsável pela introdução dos recém-chegados singulares à dinâmica do mundo comum.

A vida privada e a vida pública: Preparar épreciso

A vita activa compõe-se de três atividades no mundo contemporâneo: o trabalho, a fabricação e a ação. Arendt considera que a primeira atividade é o trabalho [lt.: animal laborans; ing.: labor], que "assegura não apenas a sobrevivência do indivíduo, mas a vida da espécie" (Arendt, 1993, p. 348). A segunda atividade é a fabricação [lt.: homo faber] "e seu produto, o artefato humano, [que] emprestam certa permanência e durabilidade à futilidade da vida mortal e ao caráter efêmero do tempo humano" (Arendt, 1993, p. 348). A terceira atividade é a "ação [gr.: zoon politikon], na medida em que se empenha em fundar e preservar corpos políticos, cria a condição para a lembrança, ou seja, para a história" (Arendt, 1993, p. 348). Assim, trabalho, fabricação e ação têm seu fundamento na "natalidade, na medida em que sua tarefa é produzir e preservar o mundo" (Arendt, 1993, p. 348). Por isso, a própria "capacidade de começar tem raiz na natalidade, e de forma alguma na criatividade, não em um dom, mas no fato de que os seres humanos, novos homens, continuamente aparecem no mundo em virtude do nascimento" (Arendt, 1993, p. 348). Nesse sentido,

se o trabalho é a atividade com a qual os homens respondem às urgências da necessidade, e se a fabricação é a atividade que responde pela produção de um mundo de artefatos duráveis que possa constituir a morada humana, a ação e o discurso, por sua vez, referem-se não apenas ao próprio exercício da vida política em comum, mas, de um modo ainda mais essencial, respondem pela própria humanização do homem e do mundo. (Duarte, 2000, p. 213) 
Como operam a educação e a escola diante das atividades da vita activa? A escola é um espaço de preparação de crianças e jovens para atuarem no mundo. Evidentemente, as crianças e jovens já são visíveis no mundo comum e já atuam sobre ele com menor ou maior intensidade de acordo com a idade que lhes dá mais ou menos acesso aos direitos sociais, civis ou políticos. Mas, para Arendt, a escola "não é de modo algum o mundo e não deve fingir sê-lo; ela é, em vez disso, a instituição que interpomos entre o domínio do privado do lar e o mundo com o fito de fazer com que seja possível a transição, de alguma forma, da família para o mundo" (Arendt, 1992, p. 238). O papel social da escola é ser intermediária entre a vida privada (trabalho) e a vida pública (fabricação e ação); promover gradualmente a inserção das crianças e jovens no mundo a partir do conhecimento das etapas do desenvolvimento cognitivo e psicológico deles; proteger e amparar as crianças e jovens da responsabilidade dos adultos na gestão do espaço público pela fabricação e pela ação. Portanto, a educação escolar "é um estágio fundamental de preparação para a ação no mundo, sendo um espaço ou esfera protopolítica: transmite conhecimentos e cultiva princípios e capacidades que favorecem a futura participação dos alunos na esfera pública" (Almeida, 2011, p. 22).

Uma ontologia da singularidade deve levar em conta que o exercício da liberdade no mundo comum precisa ser preparado na educação escolar, em que cada criança e jovem têm contato com estruturas fundantes do mundo, sem ter a responsabilidade de decidir imediatamente sobre a manutenção ou não das mesmas. Nesse sentido, depois do processo de intermediação escolar, os recém-chegados precisam estar preparados para o exercício da ação, agindo com a liberdade no mundo, que é a essência da política, uma vez que "o preceito de liberdade foi criado ao mesmo tempo, e não antes, que o homem” (Arendt, 2005, p. 190). A singularidade inicial vai se tornar, no espaço público, uma potente pluralidade, um exercício de poder, ou seja, a capacidade humana de agir em concerto, uma vez que

o poder não é sinônimo de opressão nem de coerção, mas de aptidão humana para viver na pluralidade. Ele é sempre potencial: exerce-se na relação entre os homens, pelo diálogo aberto à multiplicidade de perspectivas. A sua geração depende, então, da existência do espaço público e da pluralidade, da diversidade de opiniões e de manifestações, na qual cada indivíduo singular se revela a si próprio e aos outros, através da fala, buscando a persuasão, o convencimento pelo melhor argumento. A pluralidade e o mundo comum tornam a política possível a partir da liberdade e da igualdade acessíveis a todos os cidadãos. (Schio, 2006, p. 197)

A ontologia da singularidade fundada na natalidade culmina na ontologia da pluralidade, no espaço público, no mundo comum. Reiteramos que sem a primeira ontologia desenvolvida plenamente - função social da educação e da escola -, pode vir a sair prejudicada a ontologia da pluralidade, na atuação dos agentes políticos no espaço público, prontos para começar e recomeçar pela ação quantas vezes forem necessárias. Por fim, Arendt nos informa que "a ação está mais intimamente relacionada com a condição humana da natalidade; o novo começo inerente a cada nascimento possui a capacidade de iniciar algo novo, isto é, de agir" (Arendt, 2005, p. 17). É por isso que "neste sentido de iniciativas todas as atividades humanas possuem um elemento de ação e, portanto, de natalidade" (Arendt, 2005, p. 17).

\section{Democracia e criatividade na escola: Incluir é preciso}

Há uma necessidade de criação de um espaço democrático para a educação das crianças e 
jovens em que a inclusão, no seu sentido mais amplo e irrestrito, seja alcançado. A escola precisa garantir, enquanto instituição social, que esteja permeada pelo poder que emana do povo (o espaço entre os homens, a possibilidade de uma vida comum), ou seja, por aquele fundamento da convivência dos homens no espaço público (Adverse, 2012, p. 432). Nesse sentido, a escola deve democratizar-se para espelhar, a priori, a sociedade politica, em seu poder. Os processos democráticos da escola são importantes auxiliares na formação das crianças e jovens e podem ser descritos como ensaiamos a seguir.

Em primeiro lugar, como não há uma determinação de uma natureza humana, um condicionamento metafísico exterior dado ao indivíduo com o qual a escola deverá lidar, a novidade está em todas as crianças e jovens. Nenhuma criança ou jovem pode ficar à margem do transcurso ensino-aprendizagem: todos têm a condição para adentrar no mundo de acordo com suas possibilidades e aptidões.

Em segundo lugar, a responsabilidade dos adultos por apresentar o mundo aos recémchegados "assume a forma de autoridade" (Arendt, 1992, p. 239). É por isso que, "em face à criança, é como se ele [o adulto] fosse um representante de todos os habitantes adultos, apontando os detalhes e dizendo à criança: Isso é o nosso mundo" (Arendt, 1992, p. 239). O que se exige dos educadores é a criatividade narracional (Aguiar, 2003). Essa designa uma capacidade competente dos professores, no ato de lidar com crianças e jovens, para descrever, contar e recontar as tradições da mundaneidade aos recém-chegados, ou seja, "criar as condições para um diálogo qualificado" (Almeida, 2011, p. 110). Não se trata, pois, de repetir os conteúdos como cadáveres revividos das tumbas do passado, mas de atualizá-los, permitindo um contato dos educandos com as soluções dadas aos problemas humanos por seus pares, nas mais diversas situações do pretérito. Para Arendt, “a principal característica desta vida especificamente humana, cujo aparecimento e desaparecimento constituem eventos mundanos, é que ela, em si, é plena de eventos que posteriormente podem ser narrados como história e estabelecer uma biografia" (Arendt, 2005, pp. 108-109).

Em terceiro lugar, o currículo escolar deve estar conectado com a tradição, que nada mais é que "o fio que nos guiou com segurança através dos vastos domínios do passado" (Arendt, 1992, p. 130). A tradição é um arcabouço de experiências validadas pela comunidade em algum momento de sua história (e pode ter sido esquecida, podendo ser trazida à tona novamente). O risco de não rememorar as tradições é o esquecimento, que enfraquece "a dimensão da profundidade na existência humana” (Arendt, 1992, p. 131), uma vez que a "memória e [a] profundidade são o mesmo, ou antes, a profundidade não pode ser alcançada pelo homem a não ser através da recordação" (Arendt, 1992, p. 131).

Portanto, vivenciar a democracia no espaço escolar exige dos adultos a responsabilidade, já que eles estão no mundo e as crianças e jovens estão em atividade de inserção gradual. Essa responsabilidade é o amor mundi, que "diz respeito à realização do ser humano, que sozinho pode muito bem ser animal laborans ou homo faber, mas, sem se dirigir a outros por meio de atos e palavras, deixa de constituir esse espaço comum que permite tornar-se realmente humano (Almeida, 2011, pp. 87-88). A educação é um cuidado com o mundo e o mundo a todos inclui: os que estão sendo preparados e aqueles que são os responsáveis por esta preparação.

\section{Escola e campo de concentração: Discursar é preciso}

A valorização de todos os recém-chegados é fundamental. Não se trata de contabilizar os chegados ao mundo, num dado frio levantado pelos censos escolares. Não se trata de calar a 
voz da novidade trazida pelo nascimento com estatísticas e planilhas educacionais. $\mathrm{O}$ mais profundo do nascimento, em Arendt, é que todo o ser humano tem uma contribuição a ser dada ao mundo. Por isso, a educação deve potencializar os recém-chegados, ou seja, ajudá-los no pleno desenvolvimento de suas habilidades da condição humana historicamente dada, para que o mundo, das pequenas comunidades às grandes cidades, dos pequenos aos grandes países, seja o resultado plenificado de todas as singularidades, tornando-se uma casa comum.

O contrário da experiência educativa, em Arendt, é o campo de concentração nazista da Segunda Guerra Mundial. Em seu livro Origens do Totalitarismo (Arendt, 2004a), ela descreveu a reificação dos judeus nos campos de extermínio, nos quais nenhum prisioneiro tinha direito ao exercício da sua individualidade, de sua singularidade, de organizar-se em uma pluralidade política, uma vez que era obrigado à mudez. O silêncio é a grande marca dos campos de concentração. A maior violência praticada nos campos foi a transformação dos prisioneiros em pessoas sem voz, sem a possibilidade do discurso.

Arendt identifica a violência com a mudez. Quando se pretende tirar o poder de uma comunidade e de seus sujeitos em pluralidade, obriga-se ao silêncio, à mudez. Nos campos de concentração, as pessoas eram coagidas através de um comando efetivo à obediência pelos funcionários. Diferente do poder - a capacidade de estarmos juntos criando uma ligação entre os homens -, a violência é "muda, e por este motivo, a violência por si só, jamais pode ter grandeza” (Arendt, 2005, p. 35). O campo de concentração é a negação da tradição ocidental da polis grega. Para Arendt, "com o ser político, o viver numa polis, significava que tudo era decidido mediante palavras e persuasão, e não através de força ou violência" (Arendt, 2005, p. 35). Com isso, "para os gregos, forçar alguém mediante violência, ordenar ao invés de persuadir, eram modos prépolíticos de lidar com as pessoas", o que era típico da vida fora da polis, "característicos do lar e da vida em família, na qual o chefe da casa imperava com poderes incontestes e despóticos" (Arendt, 2005, pp. 35-36).

A violência, quando usada no espaço público, se opõe à liberdade por sua natureza instrumental. A polis era o espaço público da liberdade, sendo que "a força e a violência" (Arendt, 2005, p. 40) eram prerrogativas do governo. Com isso, a "liberdade situa-se exclusivamente na esfera política" (Arendt, 2005, p. 40), uma vez que todos os seres humanos são sujeitos à necessidade, têm o direito de empregar a violência contra os outros; a violência é o ato pré-político de libertar-se da necessidade da vida para conquistar a liberdade no mundo. $\mathrm{Na}$ análise arendtiana da polis grega "ser livre significava, ao mesmo tempo, não estar sujeito às necessidades da vida, nem ao comando do outro e também não comandar. Não significava domínio, como também não significava submissão" (Arendt, 2005, p. 41). Não apenas na polis grega, mas também na res publica romana (a polis grega e a civitas romana), havia "a garantia contra a futilidade da vida individual, o espaço protegido contra essa futilidade e reservado à relativa permanência, senão à imortalidade, dos mortais" (Arendt, 2005, p. 66). Portanto, na tradição ocidental, negada em absoluto pelos campos de concentração, a polis e a res publica eram espaços de discurso e de ação, resultando daí que o discurso é um ato intersubjetivo, plural, coletivo, público. Assim, “a organização da comunidade que resulta do agir e falar em conjunto, e o seu verdadeiro espaço situa-se entre as pessoas que vivem juntas com tal propósito, não importa onde estejam" (Arendt, 2005, p. 211).

O campo de concentração nazista é uma experiência política que interpela a escola em sua função social. Afinal, os homens que permitiram a invenção dos campos passaram pelas escolas 
europeias. Já a escola que incentiva o diálogo entre os recém-chegados e os adultos ensaia a polis grega e res publica, atualizando-as, de alguma forma. Nesse sentido, pode evitar a atomização dos homens, o desinteresse pelo mundo, a apatia pelo político, a desolação em relação ao querer agir e até mesmo o ressentimento, combustíveis poderosos para a violência no espaço público.

Nesse sentido, podemos concluir que a ontologia da singularidade está inserida na crise da modernidade que naturalizou a violência e se desencantou com a ação. Esse desencanto, esse desinteresse, podem alimentar a violência no espaço público. É que a ação para Arendt é potência de um grupo, é o poder do grupo, a capacidade de agir em conjunto, associandose com um objetivo político relevante. Dissociados, desligados de um objetivo político comum, distantes da representação partidária-parlamentar, os homens de massa foram guiados pela ideologia e pela propaganda, sendo úteis para os movimentos totalitários no uso de sua força, de sua violência. A impotência para ação é um convite para a violência.

\section{O risco da massificação escolar: Valorizar é preciso}

A singularidade não admite uma escola da massificação. A educação nos séculos XIX e XX voltou-se para as massas, indistintas, anônimas (Gauthier \& Tardif, 2014). A questão de fundo desse processo é: educar os singulares é possível quando reduzimos a atividade escolar a números, tabelas, metas e resultados? Nesse sentido precisamos analisar o que Arendt tem a nos dizer sobre o fenômeno das massas "educadas" que optaram por seguir os preceitos do totalitarismo (e seus desdobramentos nos dias atuais). Nosso objetivo é demonstrar como a massificação pode afetar diretamente a escola, naturalizando procedimentos burocráticos, vazios em sua relação com o mundo, descomprometidos com

\section{o amor mundi.}

Para Arendt, as massas são formadas por aglomerados de seres humanos indiferentes e impotentes. Dessa forma,

o termo massa só se aplica quando lidamos com pessoas que, simplesmente devido ao seu número, ou à sua indiferença, ou a uma mistura de ambos, não se podem integrar numa organização baseada no interesse comum, seja partido político, organização profissional ou sindicato de trabalhadores. (Arendt, 2004a, p. 361)

A superfluidade das massas, que pode apresentar-se como uma capacidade de mudança rápida de opinião, se mostra "no momento da derrota em que a fraqueza inerente da propaganda totalitária se torna visível. Sem a força do movimento, seus membros cessam imediatamente de acreditar no dogma pelo qual ainda ontem estavam dispostos a sacrificar a vida" (Arendt, 2004a, p. 413). Por isso,

\footnotetext{
logo que o movimento, isto é, o mundo fictício que as abrigou é destruído, as massas revertem ao seu antigo status de indivíduos isolados que aceitam de bom grado uma nova função num mundo novo ou mergulham novamente em sua antiga e desesperada superfluidade. (Arendt, 2004a, p. 413)
}

A indiferença e a inexperiência política das massas são o ponto de partida para sua cooptação pelos movimentos totalitários. Por isso, a suposta ordem do movimento e a demonstração de sua coerência atraem a massa sem muito esforço. As massas se mobilizam para a participação dos eventos convocados pelo movimento, compartilhando suas ideias. É uma participação baseada na dominação ideológica com desprezo às tradicionais formas de participação política da sociedade civil. Por isso, a impotência, o sentimento de apatia, a inação, o ressentimento, o desprezo pelas estruturas 
políticas parlamentares, a não adesão aos partidos são as características predominantes das massas. Quando participantes do movimento, a violência se torna uma das formas de manifestação de seu ressentimento. A violência se torna uma das maneiras de adesão ao movimento. Por isso, "o totalitarismo arrebanha tão facilmente seus adeptos, seduzindo-os por meio do apelo da coerência e suposta superioridade da ideologia totalitária, que os preserva do exercício da persuasão ao substituí-la pelo desencadeamento da violência e pelo fanatismo destituído de convicções" (Duarte, 2000, p. 48). Nesse sentido, "desconcertante no sucesso do totalitarismo é o verdadeiro altruísmo dos seus adeptos" (Arendt, 2004a, p. 357).

$\mathrm{Na}$ fuga da realidade através da ideologia do movimento posta em prática,

as massas pronunciam um veredicto contra um mundo no qual são forçadas a viver e onde não podem existir, uma vez que o acaso é o senhor supremo deste mundo e os seres humanos necessitam transformar constantemente as condições do caos e do acidente num padrão humano de relativa coerência. (Arendt, 2004a, p. 421)

É por isso que a violência radical proposta pelo movimento totalitário atraía a atenção das massas e lhe permitia idealizar uma nova vida. Nessa nova vida, na atividade, no movimento era "possível exprimir frustração, ressentimento e ódio cego, uma espécie de expressionismo político que tinha bombas por linguagem" e que também "observava com prazer a publicidade dada a seus feitos estrondosos e que estava absolutamente disposto a pagar com a vida o fato de conseguir impingir às camadas normais da sociedade o reconhecimento da existência de alguém" (Arendt, 2004a, pp. 381-382).

Portanto, a análise do homem de massa de Arendt é extremamente atual. É atual porque a crise da modernidade - que envolve a educação diretamente - não acabou; antes, continua a produzir fenômenos bastante semelhantes ao totalitarismo nazista, e estamos sujeitos aos movimentos de massa baseados em práticas desumanizadoras. Por isso, a ontologia da singularidade é interpelada pela massificação: se cada recém-chegado é preparado para viver no mundo, qual tem sido a qualidade da educação para as massas? É possível reverter pela educação a superfluidade, a apatia, o ressentimento? A compreensão do que estamos fazendo talvez seja um passo à frente para não repetir os desastres políticos do passado.

\section{A educação de longa duração: Preservar é preciso}

Uma questão importante é imaginar o que para Arendt seria o ponto final da ontologia da singularidade (o término do ensino básico, atualmente) e sua imediata conexão com a ontologia da pluralidade. Evidentemente, os educadores não têm a possibilidade de avaliar os atos de seus educandos no mundo. Então, o que permanece da educação nos singulares?

A educação, como já vimos, lida com o mundo sem ser o mundo como tal. É por isso que, para Arendt, a educação atinge imediatamente a vida do espírito dos singulares pela ontologia da singularidade. A escola é um espaço para a estruturação do pensamento. A escola é um espaço para a estruturação da consciência da condição de estar no mundo. A culminância, portanto, não pode ser outra coisa que o amadurecimento da vida do espírito em que o pensar, o querer e o julgar estejam habilitados para lidar com os desafios do mundo pela ação. Em resumo, crianças e jovens ao final da preparação educacional devem estar aptos pelas "atividades mentais" a agir "num mundo de aparências" (Arendt, 2011, p. 81), sem que haja um antes e um depois, em tempos estanques. Do ponto de 
vista das crianças e jovens, o pensamento não sofre cortes, é contínuo.

Como já vimos, o oposto da escola como amor mundi se configura nas tentativas dos campos de concentração nazista em mudar a natureza humana. $\mathrm{O}$ contrário de crianças e jovens com atividades mentais cultivadas e plenamente preparados para o mundo da ação pode ser representado pelo nazista Adolf Eichmann (Arendt, 2006). Um homem surpreendente e extraordinariamente superficial, demonstrando em seu julgamento uma "incapacidade de um pensamento crítico independente" (Assy, 2015, p. 4). Ele é um antimodelo educacional, por conta da capacidade de encarnar a "banalidade do mal", por não ter a "menor dificuldade em aceitar um conjunto inteiramente diferente de regras" em que "os clichês, os lugares-comuns, a adesão a códigos convencionais e padronizados de expressão e conduta têm a função de nos proteger contra a realidade", ou seja, "contra a solicitação da atenção de nosso pensamento, que todos os acontecimentos e fatos despertam em virtude da sua existência" (Arendt, 2004b, pp. 226-227). Foi "essa total ausência de pensamento [que] atraiu o meu interesse", revela Arendt (2004b, p. 227). Eichmann, que para nós encarna o antimodelo educacional, forneceu a Arendt um “insight... a respeito da possibilidade de relacionar as atividades mentais, suas considerações éticomorais, ao campo da política, ao espaço da ação e da pluralidade" (Assy, 2015, p. 4). Ressaltamos que Eichmann expressa claramente um típico caso de fracasso escolar a longo prazo. Pelo vazio do pensamento, por sua incapacidade de agir criativamente no mundo, por sua frieza ética e moral, Eichmann hipostasia o fracasso de uma ontologia da singularidade como temos apresentado. Pela superfluidade de suas decisões e pelo acatamento cego da burocracia nazista, Eichmann nos permite perguntar: qual foi a educação recebida por este oficial nazista? Seria possível impedir o aparecimento de indivíduos desse tipo através da educação? Qual a duração na vida da educação preparatória? O que resta da vida do espírito cultivada no ensino básico?

Estas perguntas nos possibilitam entender o que é a temporalidade da educação em Arendt. Crianças e jovens têm um período preparatório para seu engajamento lúcido no mundo fático. A duração dessa preparação é bastante longa na maioria das sociedades. Por isso, a ontologia da singularidade para evitar uma separação abrupta entre preparação e inserção pela ação no mundo precisa qualificar a duração enquanto fenômeno da consciência, expressa pelo pensamento e pela ação.

Henri Bergson (1859-1941) nos auxilia a entender a consciência e sua relação com a duração. Ele enfatiza que a liberdade e os problemas relacionados a ela estão ligados a uma consideração errônea da concepção de tempo, o que nos leva a considerar os estados de consciência como homogêneos e separados. Para ele, a própria consciência deve ser compreendida como duração. Por isso, crianças e jovens em processo de preparação para o mundo comum exercitaram a liberdade de pensamento antes de serem coagidos ou obrigados a decidir responsavelmente sobre como atuar no mundo. O fato de a escola ser pré-política e, por isso mesmo, anterior ao mundo que vem posterior ao processo de ensino-aprendizagem indica que os conteúdos necessários às atividades mentais estão em estado latente. A duração do aprendido depende, então, da influência que o tema ensinado teve sobre a consciência. É a liberdade para agir no mundo. Uma educação preparatória se revela eficiente na revelação da criatividade da ação no mundo. Nesse sentido, uma base educacional criativa auxilia nas atividades mentais para além da escola. Por isso, para Bergson, nossa realidade é feita de uma mistura de multiplicidades: uma quantitativa, própria ao exterior, ao espaço, à simultaneidade e à homogeneidade; e outra qualitativa, que é característica de nossa vida 
psicológica, onde os estados conscientes se sucedem, sem que haja uma separação entre eles e onde a cada instante modificam toda a interioridade (Bergson, 1991).

Assim, entendemos mais uma vez que a ação está ligada ao nascimento, ao renascimento metaforicamente colocado - agir infinitas vezes, recomeçando pelo pensamento -, ou seja, defrontados com o mundo precisamos reinventar as motivações de estar no próprio mundo. $\mathrm{O}$ mundo não repete o funcionamento determinista da natureza e é por isso que temos a possibilidade de sermos singulares, agindo com a espontaneidade própria de quem aprendeu o que é o mundo: obra de nossas próprias mãos. Então: o que somos (e como agimos nós) nesse tempo de agora, senão uma revelação da nossa vida do espírito?

\section{CONSIDERAÇÕES FINAIS}

Educar é singularizar, singularizar é educar. Singularizar/educarépreparar da melhor maneira possível crianças e jovens recém-chegados à vida em comum para agir com liberdade no mundo. A ontologia da singularidade guarda estreita relação com a educação. Afetamos pela educação o mundo e isso significa que "todos os aspectos da condição humana têm alguma relação com a política” (Arendt, 2005, p. 15).

A ontologia da singularidade é possível porque educamos. É na educação, através da escola, que podemos promover a renovação do mundo em que vivemos. A singularidade é a matéria-prima da escola. É na possibilidade de interação entre adultos e recém-chegados que o singular, o novo, os inéditos podem se revelar, trazendo ao mundo comum o confronto com a renovação e com as escolhas realizadas e sedimentadas pela tradição.

A ontologia da singularidade é política, pois evoca a originalidade de todos os recémchegados. Afirmar que cada criança nascida no mundo é original é um ato de empoderamento radical do nascimento biológico. A escola é empoderada, simultaneamente: ela é lugar, o espaço, a esfera onde a preparação imediata para a ação livre no mundo é gestada. Os professores têm grande poder: são eles responsáveis por apresentar o mundo, dialogar sobre ele, mostrar suas qualidades e defeitos. A partir da autoridade dos professores, a vida do espírito, as atividades mentais podem ser aprimoradas, podem gerar a novidade de novos recomeços.

Esclarecemos que uma ontologia da singularidade afirma a natalidade, o nascimento como uma condição humana. Ela se faz no conflito entre o novo e o velho, entre o adulto e as crianças, entre os que usam da violência para o domínio e os que incentivam o poder para criar um mundo comum mais aceitável para a pluralidade humana.

Nos seis pontos para uma ontologia da singularidade destacamos que é preciso:

1) acolher, ou seja, a vita activa é uma condição humana iniciada com o nascimento e a educação será responsável pela introdução dos recém-chegados singulares à dinâmica do mundo comum;

2) preparar, ou seja, o papel social da escola é ser intermediária entre a vida privada (trabalho) e a vida pública (fabricação e ação); promover gradualmente a inserção das crianças e jovens no mundo, a partir do conhecimento das etapas do desenvolvimento cognitivo e psicológico deles; é proteger e amparar as crianças e jovens da responsabilidade que os adultos já possuem diante das leis, o que os responsabiliza à gestão do espaço público pela fabricação e ação; é proteger e amparar as crianças e jovens $\mathrm{da} /$ na responsabilidade que os adultos já possuem diante das leis, obrigando-os à gestão do espaço público pela fabricação e pela ação;

3) incluir, ou seja, a escola deve democratizarse para espelhar, a priori, a sociedade política 
em seu poder, uma vez que nenhuma criança ou jovem pode ficar à margem do transcurso ensino-aprendizagem. Para isso, exige-se dos educadores a criatividade narracional, um diálogo criativo e qualificado e que o currículo escolar esteja conectado com a tradição. Por isso, incluir é entender a educação como amor mundi;

4) discursar, ou seja, a escola é um espaço para a visibilidade dos singulares, para os primeiros ensaios da palavra, do discurso. A escola é um espaço para a afirmação da identidade, para a sedimentação da certeza de que se tem um lugar no mundo, lugar onde todos devem ter voz e vez. Por isso, identificamos que o contrário da experiência educativa em Arendt é o campo de concentração nazista;

5) valorizar, ou seja, não massificar negativamente a educação, tornando os singulares apenas números e planilhas para os censos escolares. As massas são impotentes, apáticas, indiferentes, ressentidas. Não parece ser esse o objetivo do cuidado com o mundo. Por isso, o cuidado da escola para não alimentar os movimentos reacionários, uma vez que é a indiferença o ponto de partida para sua cooptação pelos movimentos totalitários;

6) preservar, ou seja, a educação tem o compromisso com a formação integral dos singulares para que alcancem a capacidade de agir no mundo com autonomia, criticando as ideologias e o vazio do pensamento. Nesse sentido, Henri Bergson nos auxiliou a entender que a consciência tem continuidade, latência, duração: o fato de a escola ser anterior ao mundo indica que os conteúdos necessários às atividades mentais estão em estado latente. A duração do aprendido depende, então, da influência que o tema ensinado teve sobre a consciência. A educação tem um antimodelo: Adolf Eichmann.

Acreditamos ter apresentado alguns pontos para uma reflexão acerca da possibilidade de uma ontologia da singularidade em relação direta com a educação, a fim de aprofundar a discussão que aparece incipiente em alguns estudiosos arendtianos.

\section{REFERÊNCIAS}

Adverse, H. (2012). Arendt, a democracia e a desobediência civil. Revista Brasileira de Estudos Políticos, 105, 409-434.

Aguiar, O. A. (2003). Pensamento e narração em Hannah Arendt. In E. J. de Moraes \& N. Bignotto (Orgs.), Hannah Arendt: Diálogos, reflexões, memórias (pp. 215-226). Belo Horizonte, Ed. UFMG.

Aguiar, O. A. (2008). Condição humana e educação em Hannah Arendt. Educação $e$ Filosofia, 44, 23-42.

Almeida, V. S. (2011). Educação em Hannah Arendt: Entre o mundo deserto e o amor ao mundo. São Paulo: Cortez Editora.

Arendt, H. (1992). Entre o passado e o futuro. São Paulo: Perspectiva.

Arendt, H. (1993). A vida do espírito: O pensar, o querer, o julgar. Rio de Janeiro: RelumeDumará.

Arendt, H. (2004a). Origens do totalitarismo. São Paulo: Cia. das Letras.

Arendt, H. (2004b). Responsabilidade $e$ julgamento. São Paulo: Cia. das Letras.

Arendt, H. (2005). A condição humana. Rio de Janeiro: Forense Universitária.

Arendt, H. (2006). Eichmann em Jerusalém. Um relato sobre a banalidade do mal. São Paulo: Cia. das Letras.

Arendt, H. (2011). A vida do espírito. Volume I. Pensar. Lisboa: Instituto Piaget.

Assy, B. (2015). Ética, responsabilidade e juízo em Hannah Arendt. São Paulo: Perspectiva.

Bergson, H. (1991). Essai sur les données immédiates de la conscience. Paris: PUF.

Cavarero, A., \& Butler, J. (2007). Condição 
humana contra "natureza". Estudos Feministas, 15, 647-662.

Correia, A. (2010). Natalidade e amor mundi: Sobre a relação entre educação e política em Hannah Arendt. Educação e Pesquisa, 3, 811822.

Cunha, A. G. (1986). Dicionário etimológico Nova Fronteira da língua portuguesa. Rio de Janeiro: Nova Fronteira.

Dewey, J. (1971). Democracia e educação. Introdução à filosofia da educação. São Paulo: Ed. Nacional.

Duarte, A. (2000). O pensamento à sombra da ruptura: Política e filosofia em Hannah Arendt. São Paulo: Paz e Terra.

Ferreira, A. B. H. (1975). Novo dicionário da língua portuguesa. Rio de Janeiro: Nova Fronteira.

Gauthier, C., \& Tardif, M. (2014). A pedagogia. Teorias e práticas da Antiguidade aos nossos dias. Petrópolis: Vozes.

Houaiss, A., \& Villar, M. S. (2001). Dicionário Houaiss da língua portuguesa. Rio de Janeiro: Objetiva.

Rodrigues, L. A. R. (2008). A dimensão política da escola em Gramsci e Hannah Arendt: Uma tentativa de articulação com a democracia. Trabalho \& Educação, 2, 13-30.

Schio, S. M. (2006). Hannah Arendt: História e liberdade (da ação à reflexão). Caxias do Sul: Educs.

Seixas, R. L. (2009). Ação plural, singularidade e poder em Hannah Arendt. Intuitio, 1, 201216.

Vicente, J. J. N. B. (2010). Natureza humana e totalitarismo. Griot - Revista de Filosofia, 1, 47-56.
ONTOLOGY OF SINGULARITY AND education in Hannah Arendt: A PREPARATION FOR THE WORLD

\section{Abstract}

We investigate in Hannah Arendt's thinking the possibility of an ontology of singularity directly related to education, as protomoment of the ontology of plurality, initiated with the birth and enlarged by the arrival to the common world, to the space of action. We highlight some points of her political theory interrelating them with notes on education of the text The Crisis of Education, 1958. We present education as a privileged space of formation of the life of the mind, essential, for being initial, in time and space for the full exercise of the vita activa. The ontology of the singularity is based on six points in which it is necessary: to welcome, to prepare and to include the singular ones; to create spaces to promote discourse, to value differences, and to preserve tradition. We present two antimodels for the ontology of singularity: in school education, the concentration camps, by the prerogative of the use of violence and dumbness; for the pupils, Adolf Eichmann, due to his emptiness of thought and incapacity to act creatively in the world. We propose that the duration of education is proportional to the narrative creativity of tradition by the authority of teachers.

KEY-WORDS: Hannah Arendt; Ontology of singularity; Philosophy of education; Life of the spirit 


\section{LA ONTOLOGÍA DELA SINGULARIDAD}

\section{Y LA EDUCACIÓN EN HANNAH ARENDT:}

UNA PREPARACIÓN PARA EL MUNDO

\section{RESUMEN}

Investigamos en el pensamiento de Hannah Arendt la posibilidad de una ontología de la singularidad relacionada directamente con la educación, como protomomento de la ontología de la pluralidad, iniciada con el nacimiento y ampliada por la llegada al mundo común, al espacio de la acción. Destacamos algunos puntos de su teoría política interrelacionándolos con apuntes sobre educación del texto La Crisis de la Educación, de 1958. Presentamos la educación como espacio privilegiado de formación de la vida del espíritu, esencial, por ser inicial, en tiempo y espacio para el ejercicio pleno de la vita activa. La ontología está fundamentada a partir de seis puntos en que es preciso: acoger, preparar e incluir a los singulares; fomentar espacios para el discursar, valorar las diferencias y preservar la tradición. Presentamos dos antimodelos para la ontología de la singularidad: en la educación escolar, los campos de concentración, por la prerrogativa del uso de la violencia y de la mudez; para los educandos, Adolf Eichmann, a causa de su vacío de pensamiento e incapacidad de actuar creativamente en el mundo. Proponemos que la duración de la educación es proporcional a la creatividad narrativa de la tradición por la autoridad de los profesores.

Palabras-Clave: Hannah Arendt; Ontología de la singularidad; Filosofía de la educación; Vida del espíritu

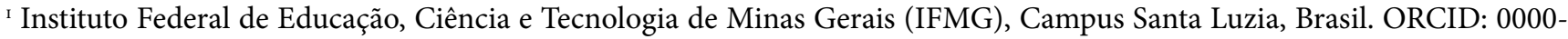
0002-7652-1959
} 